\title{
Diabetologia at 50: celebrating half a century of progress in diabetes research and care
}

\author{
Juleen R. Zierath ${ }^{1,2,3}$
}

Published online: 27 May 2015

(C) Springer-Verlag Berlin Heidelberg 2015

The colourful cover of this issue of Diabetologia celebrates our prestigious journal's golden anniversary-50 years publishing ground-breaking diabetes research, both basic and clinical and from all over the world.

\section{Diabetologia's beginnings}

Diabetologia is the official journal of the European Association for the Study of Diabetes (EASD). The EASD itself celebrated its golden anniversary in April of this year, having been founded in 1965 on the occasion of its first Annual Meeting in Montecatini, Italy. Those visionary diabetologists were keen that an association should be formed, together with a European scientific journal for diabetology. Karl Oberdisse (Düsseldorf) was particularly enthusiastic about establishing the journal 'in order to facilitate the exchange of information and experience amongst European workers,' as he wrote on the first page of Diabetologia in 1965. He was the founder of our journal and its first Editor-in-Chief for two consecutive 4-year terms of office until 1972. Since then, there have been ten more Editors-in-Chief: Karl Schöffling and Werner Creutzfeldt (1973-1976); George Alberti (19771980); Andrew Cudworth (1981-1982); Michael Berger (1983-1988); Claes Hellerström (1989-1992); Ele

Juleen R. Zierath

Juleen.Zierath@ki.se

1 Department of Molecular Medicine and Surgery, Karolinska Institutet, Von Eulers Väg 4a, 4 Tr., 17177 Stockholm, Sweden

2 Department of Physiology and Pharmacology, Karolinska Institutet, Stockholm, Sweden

3 The Novo Nordisk Foundation Center for Basic Metabolic Research, University of Copenhagen, Copenhagen, Denmark
Ferrannini (1993-1997); Werner Waldhäusl (1998-2003); Edwin Gale (2004-2010); ... and myself (2010-2015).

A committee headed by Karl Oberdisse chose the name 'Diabetologia', which enjoys several pronunciations and endures a myriad of misspellings. Springer-Verlag was asked to publish the journal, a relationship that continues to this day.

As Editor-in-Chief, Karl Oberdisse had a team of four Associate Editors, an Advisory Board of 20 and a Managing Editor. Diabetologia today has 22 Associate Editors, 18 Advisory Board members and a Managing Editor working with three editorial assistants and two copy-editors. Like my predecessors, I have endeavoured to create a team of Editors across different areas of diabetes research and with a fine balance of different nationalities, increasingly becoming more global.

Until Edwin Gale's era the Editorial Office moved around Europe with the appointment of each new Editor-in-Chief. Edwin recruited Judy Naylor as Managing Editor and together they created a strong team based in Bristol, UK, that I was delighted to be able to retain when I became Editor-in-Chief. Technology means that we are easily able to work together despite being almost 1,000 miles apart, and transport links mean that we can meet whenever and wherever necessary.

\section{Managing manuscripts and the continuous work flow}

For its first 5 years Diabetologia accepted papers written in English, French and German, and trilingual abstracts were published until 1972. Initially submissions were predominantly from Europe whereas nowadays the journal is truly international, receiving submissions from over 60 countries.

It is difficult to believe that once upon a time manuscripts were submitted on paper, sent to reviewers on paper and 
reviews were returned by post. This tedious and complex process was remarked upon by Michael Berger in his editorial marking the 20th anniversary of the journal. There was a massive change when online submission was introduced in 2005, saving forests of trees from an inky fate. This easier and more efficient process allowed decision times to be slashed despite the increased volume of submissions.

Diabetologia currently receives well over 2,000 new manuscripts annually. Consequently, the journal has had to operate an ever more stringent triage policy, with only the top $40 \%$ of papers being put forward for external peer-review. Authors whose papers are triaged will receive a decision within a few days, allowing them to submit to another journal without delay. Authors of papers that do enter the peer-review process will usually receive a first decision within a month, thanks to the hard work of our team of Editors and the dedication of our reviewers, who willingly make time in their already busy schedules in the hope that a peer will extend them the same courtesy.

The high calibre of research published in Diabetologia is reflected by the fact that the impact factor has climbed from less than 4 in 1975 to 6.88 in 2013, and we hope that authors take pride in publishing with us.

Following acceptance, a paper undergoes rigorous copyediting, proofreading and typesetting so that every aspect of its presentation has been polished when it is published in the journal. Diabetologia has undergone a design overhaul over the years and the removal of the contents list from the front cover in 2005 enabled us to produce a journal with an eye-catching and stylish cover and an equally well-crafted interior.

Until recently, 7,000 copies of the journal were printed and published every month. Excitingly, online publishing has delivered research direct to many more desks and now fewer than 100 paper issues are actually printed-long gone are the trips to the library to access research articles published within our pages.

\section{The future of diabetes research}

At the beginning of my tenure as Editor-in-Chief I commissioned a year-long series of editorials entitled 'Then and Now'. It was a chance to remember our classic, highly cited papers, describe their major findings and assess their impact on the field today. The series covered a diverse range of topics, from the innate immune system to the development of assays and algorithms. My hope was to explain how what we knew then has contributed to what we know now. In this issue, to celebrate our golden anniversary, we have commissioned a group of innovative and provocative commentaries looking 50 years into the future.
When we invited writers to contribute we encouraged them to hypothesise and conceptualise, challenging them to embrace 'blue sky, left field, out of the box thinking'! The articles were then peer reviewed and are now published in this edition.

Frans Schuit imagines comparative genomics in 2065 [1]; Nicholas Russell and Mark Cooper look at common pathways in the mechanisms of diabetic complications [2]; Mark McCarthy wonders how we might integrate genetics and genomics to provide a more accurate characterisation of the progression of the disease [3]; Frank Booth and John Hawley deplore the erosion of physical activity in Western societies [4]; Patrick Schrauwen, Wouter van Marken Lichtenbelt and Bruce Spiegelman examine research on brown adipose tissue [5] and Alison Iroz, Jean-Pierre Couty and Catherine Postic consider the role of hepatokines in the pathophysiology and treatment of type 2 diabetes [6]; Casper Schalkwijk looks at advanced glycation endproducts [7]; Michael Roden considers the role of skeletal muscle [8] and Philippe Halban focuses on beta cell studies [9]; Steven Kahn and John Buse ponder medication and how we will be treating patients in 50 years' time [10]; Bo Ahrén explores novel drugs and glucose-lowering strategies [11]; and Juris Meier and Michael Nauck ask of incretin-based drugs, 'where will we be in 50 years from now?' [12].

Marie Curie, the first person and only woman to have won a Nobel Prize twice, said: 'One never notices what has been done; one can only see what remains to be done.'

It is impossible not to look back and admire what has been achieved and appreciate how research has opened doors to new ideas, methods, awareness of disease mechanisms and development of treatments, and we hope that these visionary pieces will further inspire our readers. Perhaps for the centenary issue of Diabetologia our future editor will review this issue and evaluate what has come to fruition.

Please join me and the Editorial Office in wishing Diabetologia a very happy 50th birthday!

\section{References}

1. Schuit F (2015) Comparative genomics: beyond the horizon of the next research grant. Diabetologia. doi:10.1007/s00125-015-3620-x

2. Russell NDF, Cooper ME (2015) 50 years forward: mechanisms of hyperglycaemia-driven diabetic complications. Diabetologia. doi: 10.1007/s00125-015-3600-1

3. McCarthy MI (2015) Genomic medicine at the heart of diabetes management. Diabetologia. doi:10.1007/s00125-015-3588-6

4. Booth FW, Hawley JA (2015) The erosion of physical activity in Western societies: an economic death march. Diabetologia. doi:10.1007/s00125-015-3617-5

5. Schrauwen P, van Marken Lichtenbelt WD, Spiegelman BM (2015) The future of brown adipose tissues in the treatment of type 2 diabetes. Diabetologia. doi:10.1007/s00125-015-3611-y 
6. Iroz A, Couty J-P, Postic C (2015) Hepatokines: unlocking the multi-organ network in metabolic diseases. Diabetologia doi:10. 1007/s00125-015-3634-4

7. Schalkwijk CG (2015) Vascular AGE-ing by methylglyoxal: the past, the present and the future. Diabetologia. doi:10.1007/ s00125-015-3597-5

8. Roden M (2015) Future of muscle research in diabetes: a look into the crystal ball. Diabetologia. doi:10.1007/s00125-015-3629-1

9. Halban PA (2015) 50 years forward: beta cells. Diabetologia. doi: $10.1007 / \mathrm{s} 00125-015-3601-0$
10. Kahn SE, Buse JB (2015) Medications for type 2 diabetes: how will we be treating patients in 50 years? Diabetologia. doi:10.1007/ s00125-015-3541-8

11. Ahrén B (2015) Creative use of novel glucose-lowering drugs for type 2 diabetes: where will we head in the next 50 years? Diabetologia. doi:10.1007/s00125-015-3557-0

12. Meier JJ, Nauck MA (2015) Incretin-based therapies: where will we be 50 years from now? Diabetologia. doi:10.1007/s00125-015$3608-6$ 